\title{
Long-Term Patient Satisfaction and Quality of Life After Breast- Conserving Therapy: A Prospective Study Using the BREAST-Q
}

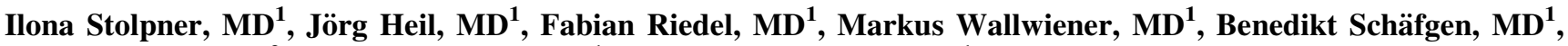 \\ Manuel Feißt, $\mathbf{M S c}^{2}$, Michael Golatta, $\mathbf{M D}^{1}$, and André Hennigs, $\mathbf{M D}^{1}$ \\ ${ }^{1}$ Department of Gynecology and Obstetrics, University of Heidelberg, Heidelberg, Germany; ${ }^{2}$ Institute of Medical \\ Biometry and Informatics, University of Heidelberg, Heidelberg, Germany
}

\begin{abstract}
Background. Poor patient-reported satisfaction after breast-conserving therapy (BCT) has been associated with impaired health-related quality of life (HRQOL) and subsequent depression in retrospective analysis. This prospective cohort study aimed to assess the HRQOL of patients who have undergone BCT using the BREAST-Q, and to identify clinical risk factors for lower patient satisfaction.
\end{abstract}

Methods. Patients with primary breast cancer undergoing BCT were asked to complete the BREAST-Q preoperatively (T1) for baseline evaluation, then 3 to 4 weeks postoperatively (T2), and finally 1 year after surgery (T3). Clinicopathologic data were extracted from the patients' charts. Repeated measures analysis of variance (ANOVA) was used to determine significant differences in mean satisfaction and well-being levels among the test intervals. Multiple linear regression was used to evaluate risk factors for lower satisfaction.

Results. The study enrolled 250 patients. The lowest baseline BREAST-Q score was reported for "satisfaction with breast" (mean, $61 \pm 19$ ), but this increased postoperatively (mean, $66 \pm 18$ ) and was maintained at the 1 year follow-up evaluation (mean, $67 \pm 21$ ). "Physical wellbeing" decreased from T1 (mean, $82 \pm 17$ ) to T2 (mean, $28 \pm 13$ ) and did not recover much by T3 (mean, $33 \pm 13$ ), being the lowest BREAST-Q score postoperatively and in

(c) The Author(s) 2021

First Received: 22 January 2021

Accepted: 21 May 2021;

Published Online: 19 July 2021

A. Hennigs, MD

e-mail: andre.Hennigs@med.uni-heidelberg.de the 1-year follow-up evaluation. In multiple regression, baseline psychosocial well-being, body mass index (BMI), and type of incision were risk factors for lower "satisfaction with breasts."

Conclusion. Both the aesthetic/surgery-related and psychological aspects are equally important with regard to "satisfaction with breasts" after BCT. The data could serve as the benchmark for future studies.

Breast cancer is the most common malignancy in women. Due to ongoing improvements of treatment methods for early-stage breast cancer, the rate of breast cancer-specific survival has never been higher than it is currently. ${ }^{1}$ With this high portion of women surviving breast cancer beyond treatment, their long-term health-related quality of life (HRQOL) has become an additional focus of outcome research. ${ }^{2}$ Studies have identified HRQOL as an important end point that provides prognostic information for medical outcomes and survival. ${ }^{3,4}$ Thus, patient-reported outcome measures (PROM) have found their way into clinical trials on a more regular basis. ${ }^{5}$

The factors of HRQOL are physical functioning, psychological well-being, and social integration. In breast cancer, findings have shown aesthetic outcome to be an additional factor influencing HRQOL. ${ }^{6,7}$ The assessment of HRQOL has become an important component of public health surveillance, and self-assessed health status also can be a more powerful predictor of mortality and morbidity than many objective measures of health. ${ }^{8,9}$

Usually, HRQOL is assessed from the perspective of the individual by a questionnaire. This subjective evaluation is sometimes viewed skeptically because the use of objective measurement parameters as an end point in clinical studies has a long tradition. However, subjectivity should not a 
priori be classified as unreliable. Symptoms reported by patients are reproducible with a very high level of validity. ${ }^{10}$

Several studies have been conducted to discover factors predicting the HRQOL of breast cancer patients. ${ }^{11-13}$ The common aim is to find possible controllable factors in order to develop targeted interventions. Influencing variables are divided into factors related to the patient, the tumor, or the treatment. General cancer-related factors, such as pain and fatigue, have been associated with worse HRQOL for patients with metastatic cancer. ${ }^{14}$ The patient-related factor of financial difficulties also has been associated with low HRQOL outcomes. ${ }^{15}$ Other factors concerning the patient's lifestyle (e.g., health literacy, access to health information, and self-efficacy in following a healthy diet or exercise) are reported as contributing to HRQOL. ${ }^{16,17}$

Whereas some studies seem to provide similar findings, other studies differ substantially in their conclusions. For example, treatment-related factors, such as the type of incision or postoperative complications, were shown to be risk factors for poor aesthetic outcomes in a prospective cohort study using the Breast Cancer Treatment Outcome Scale (BCTOS) questionnaire, ${ }^{18}$ whereas similar treatment factors were not predictive of the long-term quality of life (QoL) in another PROM. ${ }^{13}$

Inconsistencies such as these show up throughout the outcome research conducted to date. This may be due to the lack of standardization in the PROMs used in cancer research. The variability of instruments makes it difficult to compare the different studies and available data. ${ }^{19}$

The BREAST-Q questionnaire is a PROM developed especially for breast cancer patients undergoing breast surgery. Independent modules are available for the different surgical interventions (e.g., mastectomy, reconstruction, augmentation). The BREAST-Q questionnaire was developed using extensive patient input and Rasch psychometric methods. ${ }^{20,21}$ It is a psychometrically validated and reliable PROM, ${ }^{22}$ serving as a perfect candidate to fill the gap of a standardized measurement instrument. The breast-conserving therapy (BCT) module is the most recently added module, meeting the needs of this patient group. ${ }^{22,23}$

Besides the variability of the measurement instruments used, the design of most studies investigating HRQOL after breast cancer surgery might be another disadvantage. Whereas many factors associated with HRQOL have been identified in retrospective cross-sectional surveys, prospective studies with defined time frames including preoperative data at baseline still are rare. Besides, it needs to be emphasized that accurate predictions cannot be guaranteed by cross-sectional studies. Rather, the development of prediction models generally is based on cohort studies. $^{24}$
The BREAST-Q is the best PROM for this study design because each module consists of a preoperative and a postoperative questionnaire. ${ }^{25}$ Although a number of studies have evaluated the BREAST-Q in recent years, most studies using the BREAST-Q for BCT have been retrospective, cross-sectional evaluations that have not used the advantage of baseline data acquisition. ${ }^{26-30}$

In this article, we report the BREAST-Q scores for a prospective cohort of patients using the BCT module with preoperative baseline evaluation and two postoperative follow-up assessments. We analyze patient, tumor, and surgical factors predicting HRQOL.

\section{METHODS}

\section{Ethics}

The Ethics Commission of the University of Heidelberg Medical School approved the study in August 2017. The study was deemed to be without risk, including only anonymized analysis of routinely collected data. Consequently, the Ethics Committee of the University of Heidelberg did not request consent for this analysis.

\section{Study Design}

This study was designed as an exploratory, single-institution, prospective cohort study.

\section{Study Sample}

Patients were eligible for inclusion in this study if they had primary breast cancer confirmed histologically and were scheduled for BCT between July 2017 and May 2018. Patients were excluded if they opted for mastectomy, had a diagnosis of recurrence or metastasis, or declined to participate in the study.

The patients were informed about the study 1 day to 1 week before the surgery (T1). If they agreed to participate, they completed the BREAST-Q preoperative BCT module. Then, 1 week after their surgery, the patients were sent the BREAST-Q postoperative BCT module (all scales except "side effects of radiation"), together with a letter asking them to complete the questionnaire before the beginning of their radiation treatment (T2). In this way, we avoided assessing the impact of radiotherapy side effects on the HRQOL of patients at T2.

At 1 year after their surgery, the patients were sent the BREAST-Q postoperative BCT module (T3) with a letter asking them to participate in the long-term follow-up evaluation. The scales concerning the experience of care that measure satisfaction with the information provided as 
well as satisfaction with the surgeon, medical team, and office staff were assessed only once after the surgery (T2). The patients were reminded up to three times by phone to participate in the follow-up assessment. Relevant therapyrelated data were extracted from the patients' charts.

\section{Surgical Techniques Applied}

With respect to the surgical techniques, only complexity grades 1 and 2 breast-conserving procedures were applied according to the classification system of Hoffmann and Wallwiener. ${ }^{31}$ As long as no clinical involvement of the skin (which almost never occurs in these early cases of breast cancer) was suspected, we did not resect skin. To close any defect, we routinely fashioned glandular rotation flaps, mobilizing up to $25 \%$ of the glandular body. For the study cohort, there was no usage of more complex oncoplastic techniques (e.g., pedicle, free flap, fat grafts, implants, or reduction mammoplasty). The surgeon made the decision of how much volume replacement was necessary individually.

\section{Statistical Analysis}

Scores were derived for each of the BREAST-Q's domains. These were transformed to a scale of 0 to 100 according to the BREAST-Q protocol, with a higher value representing a more favorable outcome. Descriptive statistics included the mean and standard deviation and were used to compare our results with those in former literature. Repeated measures analysis of variance (ANOVA) was used to identify statistically significant differences in the mean satisfaction and well-being levels among the test intervals (baseline [T1], postoperatively [T2], and at the 1-year follow-up evaluation [T3]), with post hoc analysis determining the specifics.

The Greenhouse-Geisser adjustment was used to correct for violations of sphericity. Multiple linear regression analysis was used to identify clinicopathologic variables associated with scores at T3 on the four BREAST-Q scales ("satisfaction with breasts," "psychosocial well-being," "physical well-being," "sexual well-being”). Patients who received a secondary mastectomy between T2 and T3 were excluded from the multiple regression analysis. The regression variables were included in a forward-selection manner because this was an exploratory analysis for risk factors of an unfavorable outcome at T3. Analysis was performed using SPSS, v. 26 (IBM, Chicago, IL, USA).

\section{RESULTS}

\section{Patient Characteristics}

Between July 2017 and May 2018, 259 patients were recruited to participate in this study. Seven patients were excluded because they opted for mastectomy instead of $\mathrm{BCT}$ as their surgical procedure, and two patients were unable to complete the questionnaire because of language difficulties. Thus, 250 patients completed the preoperative questionnaire (T1) and received the postoperative module 1 week after surgery (T2). The postoperative questionnaire was returned by $219(87.6 \%)$ of the 250 patients. The follow-up questionnaire 1 year after surgery (T3) was returned by $188(75.2 \%)$ of the 250 patients. Seven patients $(2.8 \%)$ were censored from the statistical analysis of follow-up data at T3 because they had received a secondary mastectomy during the first year after the index BCT procedure.

The mean age of the cohort was $58 \pm 11$ years, and the mean BMI was $26.3 \pm 5.1 \mathrm{~kg} / \mathrm{m}^{2}$. Most of the patients had an invasive carcinoma $(88.8 \%)$ with a pT1 stage $(54.6 \%)$ but no lymph node involvement $(66.5 \%)$. Additional patient characteristics can be found in Table 1.

\section{BREAST-Q Scores of the BCT Module}

In the BREAST-Q, each scale produces an independent score from 0 to 100 and must be interpreted separately because no overall BREAST-Q score is provided. Depending on the research question, researchers and clinicians also can use only parts of the whole questionnaire because the scales are independent of each other. Furthermore, no predefined cutoffs for the score value of each scale, distinguishing between a favorable or unfavorable outcome, are provided.

For "satisfaction with breasts," the scores were the lowest at baseline (mean, $61 \pm 19$ ) and increased over time, as shown by the scores at T2 (mean, $66 \pm 18$ ) and T3 (mean, $67 \pm 21$ ) (Table 2). A repeated measures ANOVA with a Greenhouse-Geisser correction determined that the mean satisfaction levels showed a statistically significant difference between measurements $(\mathrm{F}[1.89,322.6]=6.01$; $p=0.003$ ). Bonferroni-adjusted post hoc analysis, presented in Table 3, showed a significant difference in "satisfaction with the breasts" between T1 and T2 ( $p=$ $0.045)$, as well as between T1 and T3 $(p=0.008)$.

The mean scores for "psychosocial well-being" were relatively constant, remaining the same between $\mathrm{T} 1$ (mean, $71 \pm 16)$ and T2 (mean, $71 \pm 18$ ) and increasing slightly at T3 (mean, $74 \pm 19$ ) (Table 1). Post hoc analysis did not show any significance in the change over time. 
TABLE 1 Patient characteristics at baseline $(n=250)$

\begin{tabular}{|c|c|c|}
\hline Characteristic & $n$ & $\%$ \\
\hline \multicolumn{3}{|l|}{ Histology } \\
\hline In situ carcinoma & 24 & 9.6 \\
\hline Invasive carcinoma & 223 & 89.2 \\
\hline Microinvasive carcinoma & 2 & 0.8 \\
\hline Other & 1 & 0.4 \\
\hline \multicolumn{3}{|l|}{ Neoadjuvant CHT } \\
\hline Yes & 67 & 26.8 \\
\hline No & 183 & 73.2 \\
\hline \multicolumn{3}{|l|}{ Adjuvant CHT } \\
\hline Yes & 32 & 12.8 \\
\hline No & 218 & 87.2 \\
\hline \multicolumn{3}{|l|}{ Type of surgery } \\
\hline Lumpectomy & 224 & 89.6 \\
\hline Quadrantectomy & 24 & 9.6 \\
\hline Other & 2 & 0.8 \\
\hline \multicolumn{3}{|l|}{ Type of incision } \\
\hline Radial & 46 & 18.4 \\
\hline Circular & 85 & 34.0 \\
\hline Periareolar & 104 & 41.6 \\
\hline Fishmouth-shaped & 13 & 5.2 \\
\hline Other & 2 & 0.8 \\
\hline \multicolumn{3}{|l|}{ Axillary surgery } \\
\hline SLNE only & 176 & 70.4 \\
\hline ALNE only & 46 & 18.4 \\
\hline SLNE + ALNE & 5 & 2.0 \\
\hline None & 23 & 9.2 \\
\hline \multicolumn{3}{|l|}{ (y)pN } \\
\hline No & 167 & 66.8 \\
\hline $\mathrm{N}+$ & 60 & 23.9 \\
\hline No axillary surgery performed & 23 & 9.2 \\
\hline \multicolumn{3}{|l|}{ (y)pT } \\
\hline T0 & 24 & 9.6 \\
\hline Tis/DCIS & 31 & 12.4 \\
\hline $\mathrm{T} 1$ & 137 & 54.6 \\
\hline $\mathrm{T} 2$ & 55 & 22.0 \\
\hline $\mathrm{T} 3$ & 1 & 0.4 \\
\hline $\mathrm{T} 4$ & 1 & 0.4 \\
\hline Missing data & 1 & 0.4 \\
\hline
\end{tabular}

CHT chemotherapy, SLNE sentinel lymphadenectomy, ALNE axillary lymphadenectomy, DCIS ductal carcinoma in situ

Surprisingly, the "physical well-being" scores of the BCT dropped substantially from the preoperative value (T1: mean, $82 \pm 17$ ) to the follow-up value (T2: mean, 28 \pm 13). "Physical well-being" increased slightly by T3 (mean, $33 \pm 13$ ), without reaching the baseline level. The results for "sexual well-being" showed a significant decrease from $\mathrm{T} 1$ (mean, $63 \pm 17$ ) to $\mathrm{T} 2$ (mean, $56 \pm 19$ ), reaching the baseline level at $\mathrm{T} 3$ (mean, $63 \pm 22$ ).

\section{Factors Predicting HRQOL After Breast Cancer Treatment}

Table 4 shows the factors entered into a multiple linear regression analysis to evaluate predictive factors for the satisfaction and well-being scales one year after treatment. Lower "psychosocial well-being" at baseline (T1), high BMI, and type of incision were predictive factors $(p<0.1)$ for lower "satisfaction with breasts" in the 1-year followup (T3) multiple regression analysis.

\section{DISCUSSION}

Although analysis of postoperative PROMs is continuously finding its way into research studies and outcome evaluation, surveys including evaluation of preoperative or pretreatment data still are rare. ${ }^{27}$ Our study investigated the impact of breast-conserving surgery on patients' QoL and found a significant improvement in patients' HRQoL over time on three of the four scales. Because longitudinal studies using the BREAST-Q are rare, studies to which ours can be compared are sparse. Our results are mostly consistent with those of a prospectively followed cohort from Poland by Krzos et al., ${ }^{32}$ showing that most long-term survivors of breast cancer ultimately reach QoL levels comparable with the baseline level.

In our study, the mean "satisfaction with breasts" scores were slightly higher than those of Krzos et al. ${ }^{32}$ The reported mean scores were 56.0 before surgery, 63.0 at 3 months after surgery, and 62.2 at the 1-year follow-up evaluation. ${ }^{30}$ In another study by O'Connell et al. ${ }^{30}$ evaluating 200 patients 1 to 6 years after BCT, the mean "satisfaction with breasts" score was 69.9, comparable with our results at the 1-year follow-up evaluation. Similarly, Lagendijk et al. ${ }^{27}$ reported a mean "satisfaction with breasts" score of 65.7 in a cohort of 257 patients. Dolen et al. ${ }^{33}$ reported findings with slightly higher mean scores of 61.9 before and 74.2 at 6 months after radiotherapy.

Although the increase in the scores for "satisfaction with breasts" over time was only slight in our study, this increase was statistically significant for both T2 and T3 compared with $\mathrm{T} 1$, whereas the increase between $\mathrm{T} 2$ and T3 showed no significant difference. Contrary to our initial expectations, the mean "satisfaction with breasts" score was higher immediately after surgery than before.

In a prospective cohort study with 849 patients using the Breast Cancer Treatment Outcome Scale (BCTOS) questionnaire, the aesthetic status decreased from before surgery to shortly after surgery and to the long-term 
TABLE 2 Results of the BREAST-Q BCT module

\begin{tabular}{|c|c|c|c|c|c|c|}
\hline \multirow[t]{2}{*}{ BREAST-Q scale } & \multicolumn{2}{|c|}{ T1/pre-op } & \multicolumn{2}{|c|}{ T2/3-4 weeks post-op } & \multicolumn{2}{|c|}{$\mathrm{T} 3 / 1$ year post-op } \\
\hline & $n$ & Mean \pm SD & $n$ & Mean \pm SD & $n$ & Mean \pm SD \\
\hline Satisfaction with breast & 250 & $61 \pm 19$ & 216 & $66 \pm 18$ & 179 & $67 \pm 21$ \\
\hline Psychosocial well-being & 246 & $71 \pm 16$ & 215 & $71 \pm 18$ & 181 & $74 \pm 19$ \\
\hline Physical well-being & 247 & $82 \pm 17$ & 199 & $28 \pm 13$ & 179 & $33 \pm 13$ \\
\hline Sexual well-being & 219 & $63 \pm 17$ & 182 & $56 \pm 19$ & 155 & $61 \pm 23$ \\
\hline Satisfaction with information & - & - & 199 & $60 \pm 18$ & - & - \\
\hline Satisfaction with surgeon & - & - & 186 & $73 \pm 23$ & - & - \\
\hline Satisfaction with medical team & - & - & 213 & $88 \pm 17$ & - & - \\
\hline Satisfaction with the office staff & - & - & 214 & $86 \pm 18$ & - & - \\
\hline
\end{tabular}

$B C T$ breast-conserving therapy, $S D$ standard deviation

TABLE 3 Bonferroni-adjusted post hoc analysis of the BREAST-Q BCT module

\begin{tabular}{|c|c|c|c|c|c|}
\hline & & \multicolumn{4}{|l|}{ BREAST-Q scales } \\
\hline & & Satisfaction with breast & Psychosocial well-being & Physical well-being & Sexual well-being \\
\hline \multicolumn{6}{|c|}{ Repeated measures ANOVA with a Greenhouse-Geisser correction } \\
\hline & & $\begin{array}{l}\mathrm{F}(1.89,322.64)=6.01 p=0.003 \\
\quad \text { Partial } \eta^{2}=0.03^{\mathrm{a}}\end{array}$ & $\begin{array}{l}\mathrm{F}(1.83,309.85)=3.69 p=0.03 \\
\quad \text { Partial } \eta^{2}=0.02^{\mathrm{a}}\end{array}$ & $\begin{array}{c}\mathrm{F}(1.73,264.3)=1060.34 p= \\
0.00 \text { Partial } \eta^{2}=0.87^{\mathrm{a}}\end{array}$ & $\begin{array}{l}\mathrm{F}(2,286)=13.04 p=0.00 \\
\quad \text { Partial } \eta^{2}=0.08^{\mathrm{a}}\end{array}$ \\
\hline \multicolumn{6}{|c|}{ Bonferroni-adjusted post hoc analysis, $p$ values } \\
\hline & $\mathrm{T} 2$ & $\mathbf{0 . 0 4 5}^{\mathrm{b}}$ & 1.000 & $0.000^{\mathrm{b}}$ & 0.000 \\
\hline & $\mathrm{T} 3$ & $\mathbf{0 . 0 0 8}^{\mathrm{b}}$ & 0.067 & $0.000^{b}$ & 1.000 \\
\hline \multirow[t]{2}{*}{$\mathrm{T} 2$} & $\mathrm{~T} 1$ & $0.045^{\mathrm{b}}$ & 1.000 & $0.000^{\mathrm{b}}$ & $0.000^{\mathrm{b}}$ \\
\hline & $\mathrm{T} 3$ & 0.755 & 0.134 & $0.000^{b}$ & $0.000^{b}$ \\
\hline
\end{tabular}

$B C T$ breast-conserving therapy, ANOVA analysis of variance

${ }^{\mathrm{a}}$ Partial $\eta^{2}=$ effect size, ${ }^{\mathrm{b}} p<0.05$

follow-up evaluation. ${ }^{34}$ The "aesthetic status" of the BCTOS comprises items such as "breast shape," "nipple appearance," and "scar tissue."

The main outcome measurement criterion of the BCTOS is the patients' assessment of the treated breast compared with the untreated breast, whereas the BREAST-Q explores "satisfaction with the breasts" in a more holistic way. Our findings suggest that the "satisfaction with breasts" scale of the BREAST-Q measures different aspects of surgical outcome and HRQOL than the BCTOS, with less focus on the aesthetic outcome.

A possible interpretation of our finding is that the patient's knowledge of a tumor inside her breast may lead to lower satisfaction. Thus, the satisfaction could increase after tumor removal despite an aesthetic impairment caused by the surgical procedure. Although aesthetic status is definitely part of QoL, assessment of satisfaction is superior because patients might accept worse aesthetics in exchange for tumor-free survival, being satisfied with the outcome.
In our study, BMI, preoperative psychosocial well-being, and type of incision appeared to be significant predictors of lower satisfaction with breasts at the followup evaluation. The significance of type of incision is especially interesting because it represents the relation of surgical techniques and patient satisfaction, which has already been reported in various studies. ${ }^{34-36}$ The study of O'Connell et al. ${ }^{30}$ and other studies ${ }^{37,38}$ also have identified BMI as a risk factor, but otherwise, our results in this regression analysis are not consistent with those of other studies because impaired wound healing and axillary surgery were no predictors in our analysis. This might have been due to the short time frame of 1 year for our study because the time from surgery in O'Connell et al. ${ }^{30}$ ranged from 1 to 6 years. Axillary surgery might gain a more important role with a longer time frame because lymph edema may develop later after the surgical intervention and radiation. $^{39}$

The results of the "psychosocial well-being" scales were similar at all three measurement times, without significant changes over time. This finding was consistent 
TABLE 4 Multiple linear regression analyses of the main scales in the BREAST-Q BCT module and clinicopathologic risk factors

\begin{tabular}{|c|c|c|c|c|c|c|c|c|}
\hline & \multicolumn{2}{|c|}{$\begin{array}{l}\text { T3: satisfaction } \\
\text { with breasts }(n= \\
179)\end{array}$} & \multicolumn{2}{|c|}{$\begin{array}{l}\text { T3: psychosocial } \\
\text { well-being }(n= \\
181)\end{array}$} & \multicolumn{2}{|c|}{$\begin{array}{l}\text { T3: physical well- } \\
\text { being }(n=179)\end{array}$} & \multicolumn{2}{|c|}{$\begin{array}{l}\text { T3: sexual well- } \\
\text { being }(n=155)\end{array}$} \\
\hline & $p$ Value & $\mathrm{B}$ & $p$ Value & $\mathrm{B}$ & $p$ Value & B & $p$ Value & $\mathrm{B}$ \\
\hline Model-adjusted $\mathrm{R}^{2}$ & & 0.103 & & 0.300 & & 0.200 & & 0.375 \\
\hline T1: satisfaction with breasts & 0.212 & & 0.631 & & $0.007^{\mathrm{a}}$ & -0.180 & 0.578 & \\
\hline T1: psychosocial well-being & $0.028^{\mathrm{a}}$ & 0.283 & $0.000^{\mathrm{a}}$ & 0.601 & $\mathbf{0 . 0 0 3}^{\mathrm{a}}$ & 0.224 & 0.978 & \\
\hline T1: physical well-being & 0.478 & & 0.355 & & $\mathbf{0 . 0 0 1}^{\mathrm{a}}$ & 0.214 & $\mathbf{0 . 0 0 8}^{\mathrm{a}}$ & 0.268 \\
\hline T1: sexual well-being & 0.295 & & 0.183 & & 0.582 & & $0.000^{\mathrm{a}}$ & 0.580 \\
\hline Age at surgery (years) & 0.867 & & 0.341 & & 0.155 & & 0.367 & \\
\hline BMI at surgery & $0.048^{\mathrm{a}}$ & -0.772 & 0.869 & & 0.997 & & 0.370 & \\
\hline Type of surgery (reference category, see Table 1) & 0.816 & & 0.668 & & 0.502 & & 0.620 & \\
\hline Type of incision (reference category, see Table 1) & $0.092^{\mathrm{a}}$ & -3.968 & 0.803 & & 0.510 & & 0.454 & \\
\hline Type of axillary surgery (reference category, see Table 1 ) & 0.619 & & 0.201 & & 0.992 & & $0.004^{\mathrm{a}}$ & -9.414 \\
\hline Re-excision & 0.789 & & 0.846 & & 0.912 & & 0.452 & \\
\hline Pathologic tumor size (mm) & 0.175 & & 0.559 & & 0.885 & & 0.372 & \\
\hline Resected tissue weight (g) & 0.649 & & 0.551 & & 0.342 & & 0.391 & \\
\hline pT & 0.869 & & $\mathbf{0 . 0 0 3}^{\mathrm{a}}$ & -0.315 & $\mathbf{0 . 0 5 0}^{\mathrm{a}}$ & 0.139 & 0.387 & \\
\hline $\mathrm{pN}$ & 0.374 & & 0.763 & & 0.499 & & $0.017^{\mathrm{a}}$ & 1.374 \\
\hline Neoadjuvant CHT & 0.955 & & 0.886 & & 0.802 & & 0.895 & \\
\hline Adjuvant $\mathrm{CHT}$ & 0.631 & & $0.014^{\mathrm{a}}$ & 10.039 & 0.112 & & $0.090^{\mathrm{a}}$ & 6.953 \\
\hline Endocrine therapy & 0.876 & & 0.762 & & 0.167 & & 0.824 & \\
\hline Seroma & 0.761 & & 0.120 & & $0.074^{\mathrm{a}}$ & 5.821 & $0.072^{\mathrm{a}}$ & 9.466 \\
\hline Impaired wound healing & 0.373 & & 0.752 & & 0.294 & & 0.208 & \\
\hline
\end{tabular}

$B C T$ breast-conserving therapy, $B$ regression coefficient, Model-adjusted $R 2$, adjusted coefficient of determination, $B M I$ body mass index, $C H T$ chemotherapy

${ }^{\mathrm{a}} p<0.10$

with the theory that psychological dissatisfaction goes deeper than the current situation and partially depends on personality traits,$^{40}$ which would have already been present in the preoperative inquiry. Studies and meta-analyses evaluating psychological well-being among patients have found that it can be improved with behavioral interventions ${ }^{41}$ or by successful change of personality traits. ${ }^{42}$

In our study, tumor stage was a significant predictor of psychosocial well-being. This was consistent with findings stating that receiving the diagnosis of an early stage of breast cancer already has an impact on the mental domains of HRQOL. ${ }^{43}$ Furthermore, our analysis showed that psychosocial well-being before treatment was a significant predictor of psychosocial well-being in the follow-up evaluation. This confirms the recommendations of targeted psychological interventions accompanying breast cancer therapy for high-risk groups, which are identified before treatment to prevent dissatisfaction, low psychosocial wellbeing, and consecutive depression.
The results of our study may indicate that more attention and effort should be dedicated to the long-term "psychosocial well-being" of the patients because no improvement in that scale was observed in the follow-up evaluation, although all patients were offered psycho-oncological attendance during therapy. Easy-to-implement psychological interventions have been developed and evaluated in randomized-controlled trials, with many showing positive results. ${ }^{44,45}$

The potential for developing more targeted, quantifiable interventions to be broadly disseminated is substantial. ${ }^{44,46}$ Such interventions not only would improve psychosocial well-being but also may have the potential to promote and maintain physical health.

Our results showed the greatest changes over time for "physical well-being." Although physical well-being seems to be sufficiently high before surgery (mean, $82 \pm 17$ ), a considerable decrease occurs after surgery (mean, $28 \pm 13$ ), with a slight increase in the 1-year follow-up evaluation 
(mean, $33 \pm 13$ ), without reaching baseline levels. All differences were statistically significant, showing that distinct improvement in the physical level occurs during the first year after surgery. These results do not match our expectations, and means of "physical well-being" scores reported by other studies after BCT have been noticeably higher (e.g., 67 during a follow-up period of 12 months, ${ }^{32} 78$ during a median follow-up period of 28 months, ${ }^{47} 80$ during 5 to 7 years from surgery to survey, ${ }^{26}$ and 81 during a median follow-up period of 5.5 years. ${ }^{28}$ These studies all had different time frames for the follow-up evaluation, which surely in part explains the variation in the results.

The physical well-being scores of mastectomy patients often are higher than those in our results. Howes et al. ${ }^{48}$ compared the BREAST-Q results of patients who received $\mathrm{BCT}$, mastectomy, and mastectomy with reconstruction. The BCT cohort had the lowest physical wellbeing scores, but they still were almost double the scores in our cohort. Only a study by Dolen et al. ${ }^{33}$ showed similar findings with "physical well-being of chest" scores of 49.4 in a 6-month follow-up evaluation.

All studies seem to show a general tendency of improvement over time. Although the survey by Krzos et al. ${ }^{32}$ had only a 12 -month follow-up period, their mean "physical well-being" score still showed a large difference to the score in our study. A noticeable difference was that the percentage of women receiving axillary lymph node dissection (ALND) in our study (20.4\%) was higher than in the cohort of Krzos et al. ${ }^{32}$ (12.1\%), indicating that axillary surgery might have a considerable influence on patients' physical well-being in the long term. Furthermore, confounding factors could have influenced the physical well-being in our rather heterogeneous cohort (e.g., women who received adjuvant chemotherapy or older women with more comorbidities).

More longitudinal data are needed to determine at what level the physical improvement stops and whether the baseline levels are reached again. Our data confirm that the patients need to be thoroughly advised about all possible treatment options and that $\mathrm{BCT}$, although often possible, might not be the best option for all patients regarding longterm physical well-being.

The "sexual well-being" scale had the lowest response rates at all three assessment times. In our study, the mean "sexual well-being" score decreased after surgery, with a significant difference from the baseline status. At the 1-year postoperative follow-up evaluation, the mean sexual well-being score increased to the baseline level again. This is consistent with the findings from a prospective study of women one year after BCT, which found no significant difference in female sexual dysfunction compared with a healthy control group. ${ }^{49}$ Another study evaluating breastspecific sensitivity and sexual function with regard to surgical method reached the same conclusion. ${ }^{50}$

The scales concerning satisfaction with care were administered only once, 3 to 4 weeks after surgery in our study. The "satisfaction with information" scale had the lowest score (mean, $70 \pm 18$ ), followed by "satisfaction with surgeon" (mean, $73 \pm 23$ ). Other studies show the same ranking order of the scales concerning the experience of care but higher mean scores. ${ }^{28,30}$ The timing of administration could be important for these scales. ${ }^{51}$ If the scales are administered too late, the results may be confounded by the overall satisfaction with the therapy result. If administration is too early, patients might not yet be able to review the different parts of care separately because they would still be suffering from side effects of the surgery.

Clinicians might consider administering the "satisfaction with information" scale before surgery as well as evaluating whether the patients feel sufficiently informed about the upcoming procedure. This might be especially interesting with regard to the association of positive outcomes with patient involvement and shared decisionmaking in the management of breast cancer. ${ }^{52-54}$ Administration of these scales years after treatment might be useful only to a limited extent because the scales are composed of detailed questions for which the answers might not be as memorable after a long time. Furthermore, the "satisfaction with surgeon" scale will be of advantage only in hospital systems wherein the patients have some quality interaction with their surgeon outside of surgery, and the German university hospital system does not always meet this requirement. Thus, some adaptation of that scale might be needed in case of irregular results or low response rates.

As one of its strengths, this study was one of very few longitudinal publications of the BREAST-Q BCT module including a baseline dataset and reporting on a large cohort of women. Our baseline data could be used as a benchmark for further studies until studies with a larger patient cohort are recruited (e.g., the COSMAM trial $^{55}$ ).

Among its limitations, the study was restricted to a single center with a rather homogeneous patient collective and the limited time frame. Further longitudinal research is necessary to assess the long-term evolution of patient satisfaction and well-being because breast cancer survivors have an ongoing need to process the life-changing effects of cancer. ${ }^{56}$

Because no recommendations for interpreting the results of the BREAST-Q exist to date, it is difficult to deduce clinical consequences from seemingly small differences in 
results (e.g., 5 points on the 100-point scale). As soon as sufficient benchmark data are reported in literature, the clinical meaning might become more easily deductible.

\section{CONCLUSION}

Whereas one year after surgery, breast-cancer patients treated with BCT are as psychosocially and sexually satisfied with their breasts as before treatment, the physical well-being level will not yet have reached baseline levels. Our results indicate a large need for further longitudinal research to evaluate the HRQOL of breast cancer patients with a standardized PROM that includes preoperative baseline data and follow-up assessments. The BREAST-Q can serve as a possible standard PROM in clinical practice for quality assessment and in clinical research trials because it is able to identify even slight alterations in patient satisfaction over time. However, a need still exists for more benchmark data to derive clinical consequences from BREAST-Q results.

In this study, psychosocial well-being, BMI, and type of incision were significant predictors of satisfaction with breasts, which shows that both the aesthetic and psychological aspects are important with regard to the outcomes of breast cancer surgery. High-level standardization of surgical techniques and patient-reported outcomes should be realized in subsequent prospective studies to improve outcome from the patient's perspective. Further research with controlled clinical trials is necessary to determine the specifics of the influence that different surgical incision methods have on patient satisfaction.

ACKNOWLEDGMENT We thank Michael Hanna, PhD (Mercury Medical Research \& Writing) for proofreading the manuscript and providing feedback.

FUNDING Open Access funding enabled and organized by Projekt DEAL.

DISCLOSURE There are no conflicts of interests.

OPEN ACCESS This article is licensed under a Creative Commons Attribution 4.0 International License, which permits use, sharing, adaptation, distribution and reproduction in any medium or format, as long as you give appropriate credit to the original author(s) and the source, provide a link to the Creative Commons licence, and indicate if changes were made. The images or other third party material in this article are included in the article's Creative Commons licence, unless indicated otherwise in a credit line to the material. If material is not included in the article's Creative Commons licence and your intended use is not permitted by statutory regulation or exceeds the permitted use, you will need to obtain permission directly from the copyright holder. To view a copy of this licence, visit http://creativecommons. org/licenses/by/4.0/.

\section{REFERENCES}

1. Bray F, Ferlay J, Soerjomataram I, Siegel RL, Torre LA, Jemal A. Global cancer statistics 2018: GLOBOCAN estimates of incidence and mortality worldwide for 36 cancers in 185 countries. CA Cancer J Clin. 2018;68:394-424.

2. Mols F, Vingerhoets AJ, Coebergh JW, van de Poll-Franse LV. Quality of life among long-term breast cancer survivors: a systematic review. Eur J Cancer. 2005;41:2613-9.

3. Quinten C, Coens C, Mauer M, et al. Baseline quality of life as a prognostic indicator of survival: a meta-analysis of individual patient data from EORTC clinical trials. Lancet Oncol. 2009; 10:865-71.

4. Gupta D, Granick J, Grutsch JF, Lis CG. The prognostic association of health-related quality of life scores with survival in breast cancer. Support Care Cancer. 2007;15:387-93.

5. Luckett $T$, Butow $P$, King $M$. Improving patient outcomes through the routine use of patient-reported data in cancer clinics: future directions. Psycho-oncol J Psychol Soc Behav Dimenons Cancer. 2009;18:1129-38.

6. Heil J, Czink E, Golatta M, et al. Change of aesthetic and functional outcome over time and their relationship to quality of life after breast conserving therapy. Eur J Surg Oncol. 2011;37:116-21.

7. Waljee JF, Hu ES, Ubel PA, Smith DM, Newman LA, Alderman AK. Effect of esthetic outcome after breast-conserving surgery on psychosocial functioning and quality of life. J Clin Oncol. 2008;26:3331-7.

8. Kawase K, Dimaio DJ, Tucker SL, et al. Paget's disease of the breast: there is a role for breast-conserving therapy. Ann Surg Oncol. 2005;12:391-7.

9. DeSalvo KB, Bloser N, Reynolds K, He J, Muntner P. Mortality prediction with a single general self-rated health question. $J$ Gen Intern Med. 2006;21:267.

10. Hawkins M, Elsworth GR, Osborne RH. Application of validity theory and methodology to patient-reported outcome measures (PROMs): building an argument for validity. Qual Life Res. 2018;27:1695-710.

11. Golden-Kreutz DM, Thornton LM, Gregorio W-D, et al. Traumatic stress, perceived global stress, and life events: prospectively predicting quality of life in breast cancer patients. Health Psychol. 2005;24:288.

12. Carver CS, Smith RG, Petronis VM, Antoni MH. Quality of life among long-term survivors of breast cancer: different types of antecedents predict different classes of outcomes. Psycho-oncol J Psychol Soc Behav Dimensions Cancer. 2006;15:749-58.

13. Härtl K, Engel J, Herschbach P, Reinecker H, Sommer H, Friese K. Personality traits and psychosocial stress: quality of life over 2 years following breast cancer diagnosis and psychological impact factors. Psycho-oncol J Psychol Soc Behav Dimens Cancer. 2010;19:160-9.

14. Casebeer AW, Drzayich Antol D, Hopson S, et al. Using the healthy days measure to assess factors associated with poor health-related quality of life for patients with metastatic breast, lung, or colorectal cancer enrolled in a Medicare Advantage health plan. Popul Health Manag. 2019;2:19.

15. Rautalin M, Färkkilä N, Sintonen $H$, et al. Health-related quality of life in different states of breast cancer: comparing different instruments. Acta Oncol. 2018;57:622-8.

16. Nguyen T, Seib C, Anderson D, Yate P. Lifestyle factors and health-related quality of life in Vietnamese women after cancer. Am Soc Clin Oncol. 2018;6:1698.

17. Kugbey N, Meyer-Weitz A, Asante KO. Access to health information, health literacy, and health-related quality of life among 
women living with breast cancer: depression and anxiety as mediators. Patient Educ Counsel. 2019;102:1357-63.

18. Hennigs A, Biehl H, Rauch G, et al. Change of patient-reported aesthetic outcome over time and identification of factors characterizing poor aesthetic outcome after breast-conserving therapy: long-term results of a prospective cohort study. Ann Surg Oncol. 2016;23:1744-51.

19. Howell D, Molloy S, Wilkinson K, et al. Patient-reported outcomes in routine cancer clinical practice: a scoping review of use, impact on health outcomes, and implementation factors. Ann Oncol. 2015;26:1846-58.

20. Pusic AL, Klassen AF, Scott AM, Klok JA, Cordeiro PG, Cano SJ. Development of a new patient-reported outcome measure for breast surgery: the BREAST-Q. Plast Reconstr Surg. 2009;124:345-53.

21. Cohen WA, Mundy LR, Ballard TN, et al. The BREAST-Q in surgical research: a review of the literature 2009-2015. J Plast Reconstr Aesthet Surg. 2016;69:149-62.

22. Stolpner I, Heil J, Feißt M, et al. Clinical validation of the BREAST-Q breast-conserving therapy module. Ann Surg Oncol. 2019:3:79.

23. Klassen AF, Dominici L, Fuzesi S, et al. Development and validation of the BREAST-Q breast-conserving therapy module. Ann Surg Oncol. 2020;69:1-10.

24. Steyerberg EW. Clinical Prediction Models. Berlin: Springer; 2019.

25. Builes RS, Acea NB, García NA, Cereijo C, Bouzón A, Mosquera OJ. Evaluation of the preoperative perception of quality of life and satisfaction of women with breast cancer using the BREAST$\mathrm{Q}^{\mathrm{TM}}$ questionnaire. Cirugia Espanola. 2019;3:71.

26. Jay M, Creelman B, Baliski C. Patient-reported outcomes associated with surgical intervention for breast cancer. Am J Surg. 2019;3:79.

27. Lagendijk M, van Egdom L, Richel C, et al. Patient-reported outcome measures in breast cancer patients. Eur J Surg Oncol. 2018;44:963-8.

28. Dahlback C, Ullmark JH, Rehn M, Ringberg A, Manjer J. Aesthetic result after breast-conserving therapy is associated with quality of life several years after treatment: Swedish women evaluated with BCCT.core and BREAST-Q. Breast Cancer Res Treat. 2017;164:679-87.

29. Fuzesi S, Cano SJ, Klassen AF, Atisha D, Pusic AL. Validation of the electronic version of the BREAST-Q in the army of women study. Breast. 2017;33:44-9.

30. O'Connell RL, DiMicco R, Khabra K, et al. Initial experience of the BREAST-Q breast-conserving therapy module. Breast Cancer Res Treat. 2016;160:79-89.

31. Hoffmann J, Wallwiener D. Classifying breast cancer surgery: a novel, complexity-based system for oncological, oncoplastic, and reconstructive procedures, and proof of principle by analysis of 1225 operations in 1166 patients. BMC Cancer. 2009;9:1-9.

32. Krzos A, Stanisławek A, Jędrych M, Łuczyk M, Ślusarska B. Satisfaction with the aesthetic effect and quality of life for women after breast conserving therapy (BCT): preliminary research. Int J Environ Res Public Health. 2019;16:4682.

33. Dolen U, Thornton M, Tenenbaum MM, et al. A prospective cohort study to analyze the interaction of tumor-to-breast volume in breast conservation therapy versus mastectomy with reconstruction. Breast Cancer Res Treat. 2020;181:611-21.

34. Hennigs A, Biehl H, Rauch G, et al. Change of patient-reported aesthetic outcome over time and identification of factors characterizing poor aesthetic outcome after breast-conserving therapy: long-term results of a prospective cohort study. Ann Surg Oncol. 2016;23:1744-51.

35. Heil J, Riedel F, Golatta M, Hennigs A. Measurement and optimizing cosmetic outcomes for breast excisions/factors influencing aesthetic outcomes of breast conservation surgery. Oncoplastic Breast Surgery Techniques for the General Surgeon. 2020;5:93-106.

36. Kaviani A, Sodagari N, Sheikhbahaei S, et al. From radical mastectomy to breast-conserving therapy and oncoplastic breast surgery: a narrative review comparing oncological result, cosmetic outcome, quality of life, and health economy. ISRN Oncol. 2013;2013:742462.

37. Atisha DM, Rushing CN, Samsa GP, et al. A national snapshot of satisfaction with breast cancer procedures. Ann Surg Oncol. 2015;22:361-9.

38. Rojas K, Matthews N, Raker C, et al. Body mass index (BMI), postoperative appearance satisfaction, and sexual function in breast cancer survivorship. $J$ Cancer Survivorship. 2018;12:127-33.

39. Ozaslan C, Kuru B. Lymphedema after treatment of breast cancer. Am J Surg. 2004;187:69-72.

40. Carver CS, Smith RG, Antoni MH, Petronis VM, Weiss S, Derhagopian RP. Optimistic personality and psychosocial well-being during treatment predict psychosocial well-being among long-term survivors of breast cancer. Health Psychol. 2005;24:508.

41. Weiss LA, Westerhof GJ, Bohlmeijer ET. Can we increase psychological well-being? The effects of interventions on psychological well-being: a meta-analysis of randomized controlled trials. PloS One. 2016;11:6985.

42. Hudson NW, Fraley RC. Changing for the better? Longitudinal associations between volitional personality change and psychological well-being. Person Soc Psychol Bull. 2016;42:603-15.

43. Euhus DM, Addae JK, Snyder CF, Canner JK. Change in healthrelated quality of life in older women after diagnosis of a small breast cancer. Cancer. 2019;125:1807-14.

44. Bolier L, Haverman M, Westerhof GJ, Riper H, Smit F, Bohlmeijer E. Positive psychology interventions: a meta-analysis of randomized controlled studies. BMC Public Health. 2013;13:119.

45. Trudel-Fitzgerald C, Millstein RA, von Hippel C, et al. Psychological well-being as part of the public health debate? Insight into dimensions, interventions, and policy. BMC Public Health. 2019;19:1-11.

46. Oliver JJ, MacLeod AK. Working adults' well-being: an online self-help goal-based intervention. J Occup Organ Psychol. 2018;91:665-80.

47. Gardfjell A, Dahlbäck C, Åhsberg K. Patient satisfaction after unilateral oncoplastic volume displacement surgery for breast cancer, evaluated with the BREAST-Q. World J Surg Oncol. 2019;17:96.

48. Howes BH, Watson DI, Xu C, Fosh B, Canepa M, Dean NR. Quality of life following total mastectomy with and without reconstruction versus breast-conserving surgery for breast cancer: a case-controlled cohort study. J Plast Reconstr Aesthet Surg. 2016;69:1184-91.

49. Aerts L, Christiaens MR, Enzlin P, Neven P, Amant F. Sexual functioning in women after mastectomy versus breast-conserving therapy for early-stage breast cancer: a prospective controlled study. Breast. 2014;23:629-36.

50. Gass JS, Onstad M, Pesek S, et al. Breast-specific sensuality and sexual function in cancer survivorship: does surgical modality matter? Ann Surg Oncol. 2017;24:3133-40.

51. Sepucha KR, Langford AT, Belkora JK, et al. Impact of timing on measurement of decision quality and shared decision-making: longitudinal cohort study of breast cancer patients. Med Decis Making. 2019;39:642-50.

52. Schrager S, Ovsepyan V, Burnside E. Breast cancer screening in older women: the importance of shared decision-making. $J \mathrm{Am}$ Board Fam Med. 2020;33:473-80. 
53. Ganz PA, Balogh E. Delivering high-quality cancer care: charting a new course for a system in crisis. Washington, DC: Inst Med Natl Acad; 2013.

54. Kehl KL, Landrum MB, Arora NK, et al. Association of actual and preferred decision roles with patient-reported quality of care: shared decision-making in cancer care. JAMA Oncol. 2015;1:50-8.

55. Catsman CJ, Beek MA, Voogd AC, Mulder PG, Luiten EJ. The COSMAM trial: a prospective cohort study of quality of life and cosmetic outcome in patients undergoing breast-conserving surgery. BMC Cancer. 2018;18:456.

56. Smith TM, Ratcliff K, Perry RA. Experiences with a cognitive rehabilitation program for five female breast cancer survivors: a focus group study. Ann Int Occup Ther. 2019;2:152-9.

Publisher's Note Springer Nature remains neutral with regard to jurisdictional claims in published maps and institutional affiliations. 